\title{
Actinomicose da Mama em Gestante
}

\author{
Actinomycosis of the Breast in Pregnancy \\ Juvenal Mottola Jr, Cristina Paula Castanheira, Helder Ribeiro, \\ Fábio Martins Laginha, José Antônio Marques
}

\begin{abstract}
RESUM0
A actinomicose mamária é doença inflamatória rara, com poucos casos descritos na literatura. Pode ser primária da mama quando resultante de traumas na pele e papila mamária, e, secundária, quando de origem toracopleural. Sua apresentação clínica é variável, devendo ser diferenciada das doenças mais comuns, dentre elas as mastites e também as neoplasias, como o carcinoma inflamatório. Seu diagnóstico é realizado pela cultura da secreção, com a identificação das colônias de Actinomyces sp. Seu tratamento é a drenagem, quando indicada, a antibioticoterapia endovenosa e manutenção oral por tempo prolongado. Os autores relatam caso de abscesso retromamário por Actinomyces sp. em gestante de 12 semanas que apresentava tumoração mamária expansiva na mama esquerda.
\end{abstract}

PALAVRAS-CHAVE: Actinomicose. Complicações da gravidez. Mama: infecções.

\section{Introdução}

A actinomicose mamária é doença rara que pode ser incluída entre as doenças inflamatórias crônicas da mama ${ }^{1}$. Pode ser primária, resultante de traumas na pele e na papila mamária, ou secundária à doença toracopleural, disseminando-se por meio da formação de fístulas na parede torácica $^{2}$. Sua apresentação clínica é variável, devendo ser diferenciada das doenças mais comuns, como as mastites e as neoplasias, entre elas o carcinoma inflamatório ${ }^{3}$.

O principal agente etiológico é o Actinomyces israelii, bactéria anaeróbia, Gram-positiva, que acomete, principalmente, indivíduos com doença dentária e periodôntica ${ }^{4}$.

O diagnóstico é realizado, principalmente, pela citologia e pela cultura da secreção, com a identificação de colônias bacterianas ${ }^{4}$, e seu tratamento consiste em altas doses de antibióticos por via endovenosa e manutenção por via oral prolongadamente ${ }^{2,4}$.

No presente estudo, os autores relatam o caso de gestante de 12 semanas com abscesso retromamário por Actinomyces sp., secundário à doença torácica.

Serviço de Mastologia do Centro de Referência de Saúde da Mulher - Hospital Pérola Byington, São Paulo.

Correspondência:

Juvenal Mottola Jr

Rua Aluísio Azevedo 318/32

02021-030 - São Paulo - SP

email: jmottola@uol.com.br

\section{Relato do Caso}

CCN, 29 anos, branca, procedente de São Paulo, gestante de 12 semanas, com queixa de aumento do volume e dor na mama esquerda há 22 dias acompanhada de dor no membro superior esquerdo, tendo logo após apresentado tosse produtiva e dispnéia. Ao exame físico, apresentava tumoração expansiva, com hiperemia e calor local, ocupando todo o quadrante superior e medial da mama esquerda e que atingia a região esternal (Figura 1). Apresentava má condição dentária e gengival com cáries e doença periodôntica.

Para esclarecimento diagnóstico foi submetida à ultra-sonografia mamária e à punção aspirativa por agulha, havendo saída de secreção purulenta que foi encaminhada para cultura e exame citológico. A ultra-sonografia revelou formação de conteúdo heterogêneo ocupando toda a mama esquerda. O exame citológico foi negativo para células neoplásicas e compativel com processo inflamatório supurativo, com a presença de colônias bacterianas com ramificações filamentosas sugestivas de actinomicose. $\mathrm{Na}$ cultura houve crescimento de colônias de Actinomyces sp. (Figura 2).

Para melhor avaliação da extensão do comprometimento mamário e torácico, a paciente foi submetida à tomografia computadorizada do tórax, que demonstrou formação sólida com líquido espesso retromamário com extensão, por fistulização, para a musculatura torácica e lobo superior do pulmão esquerdo (Figura 3 ). 


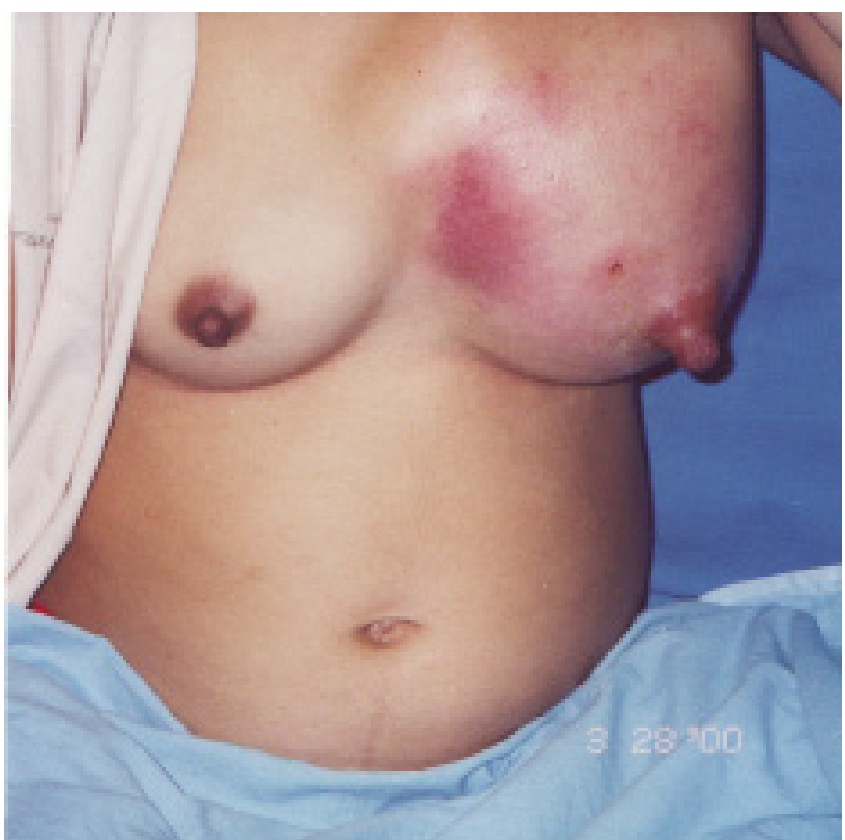

Figura 1 - Aspecto clínico da tumoração inflamatória expansiva. Quadrante superior e medial da mama esquerda e região esternal.

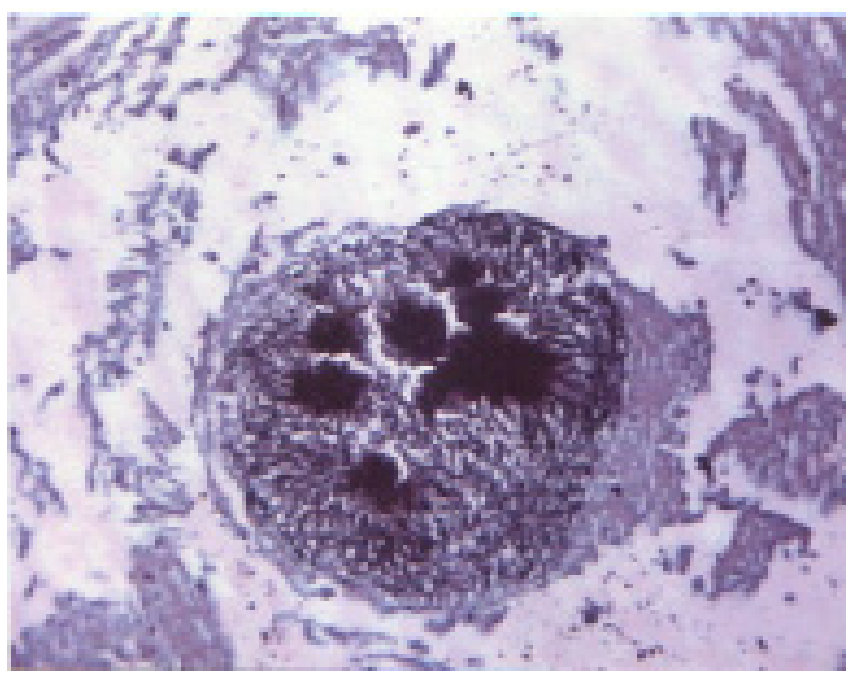

Figura 2 - Colônia de Actinomyces sp. (Coloração PAS. Aumento 100X).

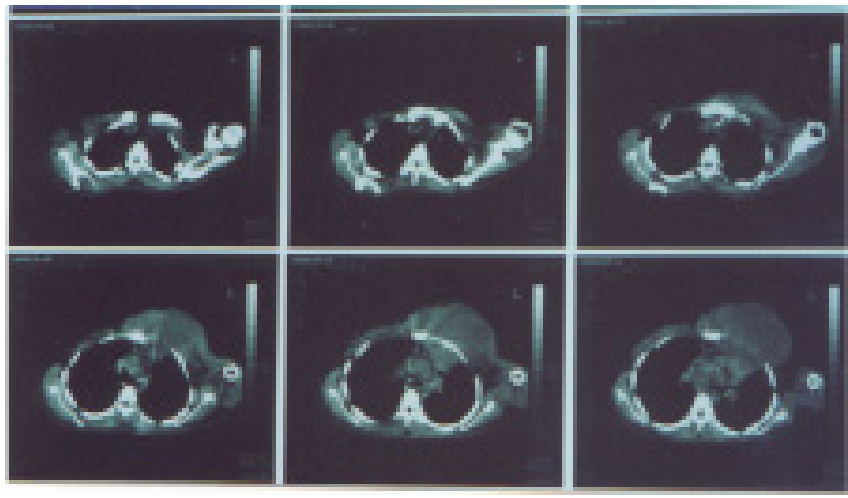

Figura 3 - Tomografia de tórax com fistulização para a parede torácica e formação sólida com líquido espesso retromamário.
Optou-se pelo tratamento com altas doses de ampicilina endovenosa $(50 \mathrm{mg} / \mathrm{kg} / \mathrm{dose}-4$ doses ao dia) por 3 semanas e pela drenagem cirúrgica da mama, com a saída de $1000 \mathrm{~mL}$ de secreção purulenta acinzentada. Após este período foi mantida a ampicilina por via oral durante três meses.

A paciente apresentou melhora do quadro doloroso, com diminuição do volume da tumoração e remissão da dispnéia. Durante o tratamento foi realizado o controle ultra-sonográfico da gestação que manteve sua evolução dentro dos padrões de normalidade. A paciente evoluiu, sem complicações, para parto normal com 39 4/7 semanas de gestação. O recém-nascido do sexo feminino recebeu Apgar 9 e 10 e pesou $3.240 \mathrm{~g}$.

\section{Discussão}

O Actinomyces é uma bactéria anaeróbia Gram-positiva, não álcool-ácido resistente, que faz parte da flora normal da cavidade oral, do trato gastrointestinal e da vagina. Determina infecções crônicas com resposta inflamatória ou granulomatosa, com quatro formas clínicas diferentes: cervicofacial, toracopleural, abdominal e disseminada. Sua prevalência não se relaciona com idade, raça, clima ou ocupação 4 .

Produz doença por meio de solução de continuidade, disseminando-se pela formação de trajetos fistulosos, sendo rara a disseminação hematogênica. Atinge, principalmente, indivíduos com doença dentária ou periodôntica, uma vez que nestes se perde a integridade da mucosa oral ${ }^{3,4}$.

$\mathrm{Na}$ actinomicose pleuropulmonar a disseminação ocorre pela formação de trajetos fistulosos, podendo se estender à região mamária, ocasionando abscessos retromamários ou intramamários ${ }^{4,5}$. A actinomicose mamária é rara, sendo muitas vezes confundida com abscessos intratáveis da mama e com o carcinoma inflamatório ${ }^{3,6}$.

O diagnóstico da doença é difícil e geralmente retardado pela sua raridade e pela baixa efetividade dos métodos utilizados ${ }^{7}$. Geralmente este diagnóstico é feito pela cultura da secreção, apesar de esta só se mostrar positiva em aproximadamente metade dos casos. Na análise histológica do material obtido na punção por agulha pode-se encontrar os "grânulos de enxofre" que representam as colônias de Actinomyces e são sugestivos da infecção por esta bactéria ${ }^{3}$.

O tratamento é realizado com altas doses de antibióticos por tempo prolongado, de 3 a 6 meses, inicialmente por via endovenosa, podendo-se conforme a evolução administrá-los por via oral. A dro- 
ga de escolha é a penicilina e a drenagem cirúrgica é necessária nos abscessos de grande volume ${ }^{2,6}$.

No presente estudo o diagnóstico sugestivo foi feito pela citologia e o definitivo pela cultura do material aspirado. Optou-se pelo tratamento com altas doses de ampicilina associado a drenagem cirúrgica em virtude da extensão do processo e das repercussões clínicas (dor local intensa e dispnéia).

Deste modo, os processos inflamatórios mamários que não melhoram com antibioticoterapia clássica para as mastites inespecíficas requerem cuidadosa investigação diagnóstica para a exclusão de processos raros como a actinomicose. As gestantes podem também ser acometidas por tais afecções, que devem ser adequadamente pesquisadas.

\section{SUMMARY}

Actinomycosis of the breast is a rare inflammatory disease that has been infrequently reported. It can be primary actinomycosis of the breast, when caused by lesions of the mammary skin and secondary, when there is thoracic or pleural infection; it has extremely variable clinical presentations and may simulate mastitis and malignancies such as inflammatory carcinoma. The diagnosis is confirmed by culture and by finding typical actinomycotic colonies. The usual treatment is surgical drainage and intravenous and oral long-term administration of antibiotics. The authors present a case of actinomycosis of the breast in a 12-week pregnant woman who presented a tumor in the left breast.

KEY WORDS: Actinomyces infection. Pregnancy. Breast.

\section{Agradecimentos:}

Ao Dr P. R. Grimaldi do laboratório Pathos, pela documentação fotográfica das colônias de Actinomyces.

\section{Referências}

1. Bland KI. Doenças inflamatórias, infecciosas e metabólicas da mama. In: Bland KI, Copeland EM, editores. Tratamento Compreensivo das Doenças Benignas e Malignas da Mama. $1^{\mathrm{a}}$ ed. São Paulo: Manole; 1994. p.110.

2. Pinto MM, Longstreth GB, Khoury GM. Fine needle aspiration of Actinomyces infection of the breast. A novel presentation of thoracopleural actinomycosis. Acta Cytol 1991; 35:409-11.

3. Teixeira JC, Shinzato JY, Cardinalli IA, Vargas RF, Brenelli HB. Actinomicose primária da mama. Rev Bras Ginecol Obstet 1995; 17:189-190.

4. Robbins SL. Patologia estrutural e funcional. $4^{\mathrm{a}} \mathrm{ed}$. São Paulo: Guanabara-Koogan; 1989. Doenças infecciosas. p.316-7.

5. Poey C, Giron J, Verhaegen F, et al. X-ray computed tomographic and radiographic aspects of thoracic actinomycosis. J Radiol 1996; 77:177-83.

6. Jain BK, Sehgal VN, Jagdish S, Ratnakar C, Smile SR. Primary actinomycosis of the breast: a clinical review and a case report. J Dermatol 1994; 21:497-500.

7. de Barros N, Issa FK, Barros AC, et al. Imaging of primary actinomycosis of the breast. AJR Am J Roentgenol 2000; 174:1784-6. 